\title{
Editorial
}

\section{La Organización Internacional del Trabajo. Un milenio de oportunidades}

La Organización Internacional del Trabajo (OIT) tiene sus raíces en la situación social de Europa y América del Norte del siglo XIX, ya que fue en estas dos regiones donde comenzó la revolución industrial. La idea de una legislación laboral internacional se abre paso en el siglo XIX sobre la base de tres argumentos: mejorar la dura existencia de las masas trabajadoras, consolidar la paz social en los países industrializados, con el fin de prevenir los conflictos sociales y revoluciones como la Revolución Rusa de 1919, y crear una regulación internacional que permitiera equiparar las condiciones de la competencia internacional.

En 1919, las naciones signatarias del Tratado de Versalles crearon la Organización Internacional del Trabajo (OIT) y plasmaron estos argumentos en el Preámbulo de la Constitución de la OIT señalando que: "Existen condiciones de trabajo que entrañan tal grado de injusticia, miseria y privaciones para gran numero de seres humanos, que el descontento causado constituye una amenaza para la paz y armonía universales. La paz universal y permanente sólo puede lograrse si se basa en la justicia social".

Tras las bases del Tratado de Versalles, el siguiente paso en la trayectoria de la OIT fue la Declaración de Filadelfia en 1944. Allí se definió que el trabajo no es una mercancía, se habló de la libertad de expresión y de asociación como algo esencial para el progreso constante y se marcó que la pobreza constituye un peligro para la prosperidad de todos. Desde entonces, se declaró que los seres humanos sin distinción de raza, credo o sexo tienen derecho a perseguir su bienestar material y su desarrollo espiritual en condiciones de libertad, dignidad, seguridad económica e igualdad de oportunidades.

Siguiendo el camino histórico de la OIT, destaca entre sus hitos el primer informe de la Conferencia Internacional del Trabajo de 1999. En esta ocasión, el Director General de la OIT, Juan Somavía señaló que: "la primera meta de la OIT es promover las oportunidades para que las mujeres y los hombres puedan obtener un empleo decente y productivo, en condiciones de libertad, igualdad, seguridad y dignidad humana”. De esta forma, el Trabajo Decente se convierte en el eje de la Organización. Para lograr la implantación del Trabajo Decente en el mundo, la OIT se dotó de un Programa de Trabajo Decente para un Crecimiento con Equidad en el que confluyen los cuatro objetivos estratégicos:

1. Promover las normas y principios fundamentales en el trabajo. Sin estas normas, los hombres y las mujeres no dispondrán de medios para escapar de la pobreza.

2. Crear mayores oportunidades para las mujeres y los hombres que aseguren un empleo digno, ya que como se señalaba anteriormente, el camino principal para salir de la pobreza es el trabajo productivo. 
3. Aumentar la cobertura y la eficacia de la protección social para todos, ya que la protección social es una garantía contra la pobreza.

4. Fortalecer el tripartismo y el diálogo social y la participación de las organizaciones de empleadores y trabajadores en la formulación de las políticas gubernamentales para la reducción de la pobreza es esencial.

5. El concepto de Trabajo Decente fue formulado por los mandantes de la OIT (gobiernos, organizaciones de empleadores y organizaciones de trabajadores) como una manera de identificar las prioridades de la Organización y de reformar y modernizar su enfoque en el siglo XXI. Este concepto se basa en el reconocimiento de que el trabajo es fuente de dignidad personal, estabilidad familiar, paz en la comunidad, de democracias que producen para las personas y de crecimiento económico que aumenta las posibilidades de trabajos productivos y el desarrollo de las empresas. En consecuencia, el Trabajo Decente se define como: "aquel trabajo productivo que cuenta con una remuneración justa, con seguridad en el lugar de trabajo y protección social para las familias, con mejores perspectivas para el desarrollo personal y la integración social, libertad para que los individuos manifiesten sus preocupaciones, se organicen y participen en la toma de aquellas decisiones que afecten a sus vidas, así como la igualdad de oportunidades y de trato para mujeres y hombres".

Como se puede ver en la definición, el Trabajo Decente refleja muchas prioridades de la agenda social, económica y política de muchos países y del sistema internacional, que se podrían sintetizar en: obtener una globalización justa, reducir la pobreza ya que la obtención de un trabajo decente es la mejor forma de salir de la pobreza y de la marginación.

El Trabajo Decente representa seguridad, ya que una comunidad que trabaja es una comunidad en paz. El trabajo decente significa la inclusión social, ya que la igualdad de oportunidades y ausencia de discriminación que implica, es crucial para lograr la realización del total de las capacidades personales.

En un periodo de tiempo relativamente breve, se ha generado un consenso internacional en torno al concepto de Trabajo Decente, apoyado por Jefes de Estado de numerosos países de Asia, América y Europa, por Naciones Unidas, por la Comisión Europea y por otras organizaciones internacionales.

Así lo entendió, la sesión de alto nivel del Consejo Económico y Social (ECOSOC) de Naciones Unidas, celebrada entre el 3 y el 5 de julio de 2006 en Ginebra, que aprobó una Declaración Ministerial de gran alcance sobre el empleo pleno y productivo y el Trabajo Decente, señalando que contribuirá a redoblar los esfuerzos de Naciones Unidas y del sistema multilateral para crear puestos de trabajo, reducir la pobreza y brindar una nueva esperanza a los 1.400 millones de trabajadores pobres del mundo, en el próximo decenio.

Juan Felipe Hunt Ortiz

Director

Oficina de la Organización Internacional del Trabajo. España 